\title{
СТРУКТУРНЫЕ ОСОБЕННОСТИ ТВОРЧЕСКИХ СПОСОБНОСТЕЙ СТУДЕНТОВ ВУЗА С РЕФЛЕКТИВНЫМ И ИМПУЛЬСИВНЫМ КОГНИТИВНЫМИ СТИЛЯМИ
}

\author{
Ирина А. Кибальченко ${ }^{1 *}$, Владимир В. Подберезный², \\ Алла И. Забалуева' \\ ${ }^{1}$ Южный федеральный университет, г. Таганрог, Российская Федерация \\ ${ }^{2}$ Таганрогский институт имени А. П. Чехова (филиал) Ростовского госу- \\ дарственного экономического университета, г. Таганрог, \\ Российская Федерачия \\ *E-mail: kibal-irina@mail.ru
}

Введение. Статья посвящена теоретическому и эмпирическому изучению структурных особенностей творческих способностей студентов, отличающихся когнитивными стилями. Авторами доказывается актуальность изучения когнитивного стиля студентов по критерию «рефлективность/ импульсивность» как предиктора творческих способностей и академической успеваемости студентов. Делается акцент на том, что когнитивный стиль представляет собой сложный личностный конструкт, который рассматривается как совокупность индивидуально специфических и устойчивых особенностей и склонностей к определенным способам переработки информации и принятия решений. Выдвинуто предположение о том, что рефлективный и импульсивный когнитивные стили студентов обладают предикторным потенциалом творческих способностей и академической успеваемости студентов.

Материалы и методы. Представлены результаты эмпирического исследования, полученные на выборке студентов вуза (юношей и девушек, средний возраст - 20 лет) в количестве 136 человек. Использованы методы обработки и анализа данных, тест «Сравнение похожих рисунков» Дж. Кагана (The Matching Familiar Figures Test, MFFT), краткий тест творческого мышления «Фигурная форма» Э. П. Торренса, тест Х. Зиверта «Определение творческих способностей».

Результаты. На основе критериев U Манна - Уитни и углового преобразования Фишера выявлены значимые различия на уровне $p<0,05$ и $p<0,01$ в показателях творческих способностей (оригинальность, беглость, гибкость, разработанность) в группах студентов с рефлективным, импульсивным, быстрым точным, медленным неточным когнитивными стилями. В прочессе факторизачии и вращения по методу Varimax диагностических 
результатов определены структурные особенности творческих способностей студентов вуза.

Обсуждение результатов. Подтверждено предположение о том, что характеристики творческих способностей студентов с такими когнитивными стилями, как рефлективный, импульсивный, быстрый точный, медленный неточный, создают структуру, характер взаимосвязей которой обусловлен склонностями к определенным способам переработки информации. Получены новые результаты, которые позволяют сделать вывод о том, что рефлективный, импульсивный и производные от них когнитивные стили студентов обладают предикторным потенциалом творческих способностей и академической успеваемости. Определены перспективы исследования ресурса творческо-стилевых структур студентов как будущих профессионалов.

Ключевые слова: творческие способности, структура творческих способностей, креативность, когнитивный стиль, рефлективность, импульсивность, предиктор, потенциал, быстрый точный стиль, медленный неточный стиль

\section{Основные положения:}

> студенты с рефлективным когнитивным стилем значимо отличаются от студентов с медленным и неточным когнитивным стилем по сформированности у них разработанности и гибкости;

> студенты с быстрым точным когнитивным стилем значимо отличаются от студентов с медленным и неточным когнитивным стилем по сформированности у них беглости, гибкости, оригинальности;

> взаимосвязи быстрого точного когнитивного стиля и творческих показателей позволяют назвать этот стиль предиктором творческих способностей студентов.

Для цитирования: Кибальченко И. А., Подберезный В.В., Забалуева А.И. Структурные особенности творческих способностей студентов вуза с рефлективным и импульсивным когнитивными стилями // Российский психологический журнал. - 2017. - Т. 14, № 3. - С. 48-69. 


\title{
STRUCTURAL FEATURES OF CREATIVE ABILITIES AMONG UNIVERSITY STUDENTS WITH REFLECTIVE AND IMPULSIVE COGNITIVE STYLES
}

\author{
Irina A. Kibal'chenko ${ }^{1 *}$, Vladimir V. Podbereznyi ${ }^{2}$, Alla I. Zabalueva' \\ 'Southern Federal University, Taganrog, Russian Federation \\ 2 Taganrog Institute named after A. P. Chekhov, Branch of Rostov State \\ University of Economics, Taganrog, Russian Federation \\ *Correspondence author. E-mail: kibal-irina@mail.ru
}

Introduction. The paper deals with a theoretical and empirical study of structural features of creative abilities among students with different cognitive styles. The study (a) reveals the importance of investigating students' cognitive style by the reflectivity/ impulsivity criterion as a predictor of their creative abilities and academic achievement, (b) emphasizes that cognitive style is a complex personal construct, a set of individual specific and stable characteristics and predispositions to certain ways of information processing and decision making, (c) assumes that students' reflective and impulsive cognitive styles can predict their creative abilities and academic achievement.

Materials and Methods. The empirical study involved 136 male and female students (mean age 20 years). The study employed methods of data processing and analysis, the Kagan Matching Familiar Figures Test (MFFT), the Torrance Tests of Creative Thinking (Figural Forms), and the Sievert Test of Creative Abilities.

Results. The Mann-Whitney U-test and angular conversion Fisher made it possible to reveal significant differences at the 0.05 and 0.01 levels of significance among the parameters of creative abilities (originality, fluency, flexibility, and elaboration) in groups of students with reflective, impulsive, fast-accurate, and slow-inaccurate cognitive styles. Factor analysis with varimax rotation revealed structural features of students' creative abilities.

Discussion. The characteristics of creative abilities among students with reflective, impulsive, fast-accurate, and slow-inaccurate cognitive styles create a structure. Predispositions to certain ways of information processing determine relationships within this structure. The obtained results suggest that reflective and impulsive cognitive styles and also their derivatives can predict students' creative abilities and academic achievement. Future work will involve studying creative and style structures in students as future professionals.

Keywords: creative abilities, structure of creative abilities, creativity, cognitive style, reflectivity, impulsivity, predictor, potential, fast-accurate style, slow-inaccurate style 


\section{Highlights}

- Flexibility and elaboration are higher in the group of students with the reflective cognitive style, than among the students with the slow-inaccurate cognitive style.

- Fluency, originality, and flexibility are higher in the group of students with the fast-accurate cognitive style, than among the students with the slow-inaccurate cognitive style.

$>$ The fast-accurate cognitive style is a predictor of students' creative abilities.

For citation: Kibal'chenko I. A., Podbereznyi V.V., Zabalueva A. I. Structural features of creative abilities among university students with reflective and impulsive cognitive styles. Rossiiskii psikhologicheskii zhurnal - Russian Psychological Journal, 2017, V. 14, no. 3, pp. 48-69 (in Russian).

Original manuscript received 31.03.2017

\section{Введение}

Изучение творческих способностей, креативности и интеллекта молодых людей в мире быстро изменяющихся условий позволяет сделать вывод о необходимости сформированности у студентов взаимосвязи интеллектуальных, познавательных, творческих способностей как интегральной основы генерации и разработки идей, способов решения сложнейших задач (В. Н. Азаров, Е. Ф. Коломиец и др.) [1, 2]. «Стартовой площадкой» [3] развития творческих способностей и креативности, по мнению многих исследователей (М. А. Холодная, И. С. Кострикина и др.), являются общий интеллект и когнитивный стиль как одна из его характеристик $[4,5,6]$. Высокий интеллект и продуктивный когнитивный стиль, как частный случай индивидуального стиля познавательной деятельности человека, и основание построения индивидуальной картины мира обусловливают интеграцию интеллекта и творчества личности [7]. А смысл ее развития в процессе обучения, по мнению М. А. Холодной, заключается в выработке у обучающихся стилевой гибкости. Под когнитивным стилем понимается многомерный личностный конструкт, рассматриваемый как совокупность индивидуально-специфических и устойчивых особенностей и склонностей (тенденций) к определенным способам переработки информации и принятия решений [8]. Способы обработки информации и решения проблем, креативное мышление являются примерами тех возможностей, которые обеспечиваются внутренними ресурсами человека [9]. К ним же относятся и такие характеристики творчества, как оригинальность, разработанность, беглость, гибкость мышления [10]. Можно предположить, что когнитивные стили обладают предикторным потенциалом структурных особенностей творческих способностей студентов. 
Под творческими способностями понимаются индивидуальные особенности качеств человека, которые определяют успешность выполнения им творческой деятельности различного рода.

С учетом мнений многих исследователей (Т. И. Виноградова, Н. Б. Шумакова, Е. И. Щебланова и др.), под способностью к творчеству понимается отклонение от традиционных схем мышления, порождение необычных идей в разных областях знаний, быстрое решение проблемных ситуаций [11, 12].

Способность к творчеству, креативность, прежде всего определяется восприимчивостью человека к новым идеям [13]. Однако в процессе изучения структуры творчества студентов с учетом их когнитивного стиля возникает некоторый диссонанс: с одной стороны, рефлективный когнитивный стиль в силу его характеристик может стать основанием творческого замедления, с другой стороны, рефлективный когнитивный стиль обеспечивает развитие интеллекта студентов, детальную проработку, исключение ошибок творчества, рефлексии. При этом, основываясь на том, что возраст студенчества сензитивен к формированию устойчивых стилей активности, в том числе и когнитивных стилей, представляется актуальным рассмотрение стилевых структур как устойчивых предикторов их творчества $[14,15,16]$.

Рефлексивное сознание и произвольный контроль связаны с научным полем понятий, основанным на общности признаков $[17,18]$. Глубина рефлексии и рефлективный стиль характеризуют индивидуальную когнитивную сложность решений субъекта. Такой факт вызывает научный и исследовательский интерес [19]. Известно, что повышение рефлективности субъекта обусловлено уровнем сформированности понятийных структур [20]. С позиций импульсивности и рефлективности, входящих в систему метакогнитивной регуляции [21], возможно более дифференцированно спрогнозировать особенности творческих способностей и креативности как общей способности к творчеству [22]. Специфика когнитивного стиля определяет условия и средства творчества студентов. Однако решение вопроса о том, каковы взаимосвязи творческих способностей студентов и их когнитивных стилей, остается открытым.

В связи с этим, теоретическая гипотеза исследования заключается в том, что характеристики творческих способностей студентов с разными когнитивными стилями (рефлективным/импульсивным) создают структуру, характер взаимосвязей которой обусловлен склонностями к определенным способам переработки информации и принятия решений. Когнитивные стили студентов обладают предикторным потенциалом творческих способностей и академической успеваемости студентов.

Эмпирические гипотезы исследования:

1. Творческие способности студентов обусловлены сформированностью у них когнитивного стиля по критерию рефлективность/импульсивность: 
- у студентов с рефлективным когнитивным стилем сформирована разработанность, как способность детально разрабатывать продуцируемые идеи, и гибкость, как способность переключаться с одной идеи на другую, в отличие от импульсивного когнитивного стиля;

- у студентов с быстрым и точным когнитивным стилем сформирована беглость, как способность генерировать большое количество идей, гибкость и оригинальность, как способность производить нестандартные идеи, в отличие от медленного неточного когнитивного стиля.

2. Рефлективный когнитивный стиль, в отличие от других рассмотренных когнитивных стилей, является предиктором высокой успеваемости студентов.

3. Быстрый точный когнитивный стиль студентов является предиктором гармоничности структуры их творческих способностей.

В нашем исследовании на основании когнитивно-стилевого подхода осуществлена попытка соотнести указанные когнитивные стили студентов с академической успеваемостью, творческими характеристиками и определить структурные особенности творческих способностей студентов.

Цель исследования - анализ взаимосвязи характеристик творческих способностей и когнитивных стилей студентов по критерию рефлективность/импульсивность (рефлективный, импульсивный, быстрый точный, медленный неточный).

Актуальность исследования обусловлена тем, что изучение структуры творческих способностей студентов с разными когнитивными стилями по критерию рефлективность/импульсивность - это попытка изучения предикторного потенциала структур их творческих способностей, обусловливающего выбор продуктивных способов решения разнообразных задач и эффективных стратегий деятельности в новых условиях [23].

\section{Материалы и методы}

В исследовании принимали участие 136 студентов (70 девушек и 66 юношей, средний возраст - 20 лет (от 19 до 21 года)) гуманитарной и технической профессиональных направленностей.

Использовались следующие методы:

1. Методы обработки и анализа данных: непараметрический статистический критерий U Манна - Уитни для определения различий в результатах между группами; угловое преобразование Фишера для сравнения двух групп по частоте встречаемости (в \%) некоторого эффекта; факторный анализ для определения структуры творческих способностей студентов с разными когнитивными стилями (SPSS-22).

2. Тест «Сравнение похожих рисунков» Дж. Кагана (The Matching Familiar Figures Test, MFFT), разработанный для диагностики когнитивного 
стиля «импульсивность/рефлективность». Участнику исследования предъявлялись 2 тренировочных листа, затем 12 основных, на каждом из которых сверху находится изображение знакомого предмета (фигура-эталон), а внизу располагаются в два ряда 8 почти идентичных изображений этого же предмета, среди которых только одно полностью идентично фигуре-эталону. Участник исследования должен найти и указать изображение. Оценка ответов проводилась с помощью ключа. Показатели импульсивности/рефлективности: латентное время ответов (сумма), общее количество ошибок. Все результаты распределялись в соответствии с осями координат «латентное время ответов», «количество ошибок». Рефлективные индивидуумы находятся выше медианы времени ответа и ниже медианы количества ошибок, тогда как импульсивные индивидуумы, напротив, ниже медианы времени ответа и выше медианы количества ошибок [24].

3. Краткий тест творческого мышления «Фигурная форма» Э. П. Торренса для диагностики творческих способностей студентов. Студентам давались бланк и инструкция: добавить к незаконченным фигурам дополнительные линии так, чтобы получились интересные предметы или картинки. Время выполнения задания - 10 минут. Обработка результатов: нерелевантные рисунки, которые не соответствуют условиям задания, т. е. не включают в себя заданные элементы, не учитываются. Остальные задания оцениваются по следующим параметрам: беглость, гибкость, оригинальность и разработанность. Беглость указывает на количество завершенных фигур. Гибкость определяется числом различных категорий ответов. Для определения категории могут использоваться как сами рисунки, так и их названия (что иногда не совпадает). Категории ответов, оцениваемых 0 или 1 баллом за оригинальность, определялись по специальному списку отдельно для каждой стимульной фигуры.

4. Тест Х. Зиверта «Определение творческих способностей» (дополнительно). Тест включает разделы, каждый из которых предназначен для проверки того или иного измерения творческих способностей по шкалам: находчивость; способность комбинировать; дивергентное (нестандартное) мышление, свобода ассоциаций; визуальное творчество; уровень творческих способностей. За ответы присваиваются баллы по ключу [25].

Для разделения студентов по успеваемости использовался критерий результативности обучения, который подразумевает низкий, средний и высокий уровни овладения учебной деятельностью. В группу с высокой успеваемостью вошли студенты, средние значения оценок которых по дисциплинам предметного цикла за учебный год составили от 4,5 до 5 баллов; в группу со средней успеваемостью вошли студенты, средние значения оценок которых за учебный год составили от 3,5 до 4,4 баллов; в группу с низкой успеваемостью - студенты, средние значения оценок которых - до 3,4 баллов включительно [26]. 


\section{Результаты}

В процессе дифференциации студентов по выраженности рефлективности и импульсивности в их когнитивных стилях (по тесту Дж. Кагана «Сравнение похожих рисунков») были выявлены четыре группы: 1) студенты, которые затратили на выполнение тестовых заданий много времени и практически не допускали ошибок, условно названы «рефлективные» (41 человек - 30\% от общей выборки); 2) студенты, которые быстро выполняли тестовые задания и допустили много ошибок, условно названы «импульсивные» (41 человек $30 \%) ; 3)$ студенты, которые долго выполняли задания, но при этом допускали большое количество ошибок - «медленные неточные» (16 человек - 12\%); 4) студенты, которые быстро выполняли тестовые задания и практически не допустили ошибок - «быстрые и точные» (38 человек - 28\%).

Известно, что рефлективные субъекты взвешивают все аргументы, собирают больше информации о стимуле перед ответом, успешно применяют приобретенные в процессе обучения стратегии деятельности в новых условиях [27]. Быстрые точные характеризуются как интеллектуально развитые, уверенные в себе, рациональные и энергичные в процессе решения задач и проблем. Медленные неточные плохо прогнозируют последствия, допускают ошибки при решении задач и проблем.

В связи с этим можно утверждать, что когнитивный стиль «импульсивность/рефлективность» является некоторой косвенной мерой соотношения разных фаз (ориентировочной, контрольной, исполнительной) в структуре интеллектуальной деятельности и в творчестве. Дополнительным фактом стало распределение студентов по успеваемости в группах с разными когнитивными стилями: рефлективные студенты в основном (69,5\%) демонстрируют высокий и средний (30,5\%) уровни академической успеваемости; импульсивные обнаруживают средний уровень (53\%) и низкий уровень (39\%), однако есть и такие, кто продемонстрировал высокий уровень успеваемости (8\%); медленные неточные продемонстрировали низкий уровень академической успеваемости (100\%); быстрые точные, напротив, в большинстве (62\%) продемонстрировали высокий, средний (32\%) и низкий (6\%) уровни академической успеваемости.

При изучении творческих способностей у студентов получены значимые различия по критерию U Манна - Уитни:

- рефлективные студенты значимо отличаются от медленных неточных студентов по разработанности $\left(U_{\text {эмп. }}=324, \mathrm{p}<0,05\right)$ и от импульсивных студентов по гибкости $\left(U_{\text {эмп. }}=324, \mathrm{p}<0,01\right.$, т. к. $\left.U_{\text {кр. }}(P<0,05)=417, \mathrm{U}_{\text {кр. }}(P<0,01)=376\right)$;

- быстрыеточныестуденты значимо отличаются от медленныхнеточныхстудентов по таким характеристикам, как гибкость, беглость, оригинальность $\left(\mathrm{U}_{\text {эмп. }}=362\right.$, $\mathrm{p}<0,01$, т. к. $\left.\mathrm{U}_{\text {кр. }}(P<0,05)=417, \mathrm{U}_{\text {кр. }}(P<0,01)=376\right)$. 


\section{Обсуждение результатов}

Результаты являются предпосылками к различиям в структурах творческих способностей, которые были получены в результате факторизации и вращения диагностических показателей по методу Varimax.

Структура творческих способностей рефлективных студентов характеризуется четырьмя факторами (\% совокупной дисперсии - 74,34) (таблица 1). Веса переменных, включенных в факторы, выделены полужирным курсивом в таблицах 1, 2, 3, 4.

Таблича 1.

\section{Факторная матрица взаимосвязей переменных творческих} способностей студентов с рефлективным когнитивным стилем (Rotation Method: Varimax with Kaiser Normalization [28])

Table 1.

Factorial matrix of associations among the variables of students' creative abilities and the reflective cognitive style (Rotation Method: Varimax with Kaiser Normalization [28])

\begin{tabular}{|c|c|c|c|c|}
\hline \multicolumn{5}{|c|}{$\begin{array}{c}\text { Mampuца компонентов }{ }^{a}(n=41) \\
\text { Components matrix }{ }^{a}(n=41)\end{array}$} \\
\hline \multirow{2}{*}{$\begin{array}{c}\text { Характеристики } \\
\text { творчества } \\
\text { Creativity } \\
\text { characteristics }\end{array}$} & \multicolumn{4}{|c|}{$\begin{array}{l}\text { Компоненты (факторы) } \\
\text { Components (factors) }\end{array}$} \\
\hline & 1 & 2 & 3 & 4 \\
\hline $\begin{array}{l}\text { Разработанность } \\
\text { Elaboration }\end{array}$ & 701 & ,346 &,- 078 &,- 127 \\
\hline $\begin{array}{l}\text { Оригинальность } \\
\text { Originality }\end{array}$ & 648 & ,042 & 372 & 070 \\
\hline $\begin{array}{l}\text { Гибкость } \\
\text { Flexibility }\end{array}$ &,- 662 & 324 & 204 & ,426 \\
\hline $\begin{array}{l}\text { Беглость } \\
\text { Fluency }\end{array}$ & 913 &,- 232 &,- 206 &,- 063 \\
\hline $\begin{array}{l}\text { Находчивость } \\
\text { Resourcefulness }\end{array}$ &,- 168 &,- 174 &,- 072 & 871 \\
\hline $\begin{array}{l}\text { Комбинирование } \\
\text { Combination }\end{array}$ & 141 & ,427 &,- 561 & 310 \\
\hline \begin{tabular}{|l|} 
Дивергентное \\
мышление \\
Divergent thinking
\end{tabular} & 185 & 911 &,- 129 &,- 092 \\
\hline \begin{tabular}{|l|} 
Визуальное \\
творчество \\
Visual creativity
\end{tabular} & ,013 &,- 014 & ,953 & 093 \\
\hline $\begin{array}{l}\text { Свобода ассоциаций } \\
\text { Freedom of association }\end{array}$ &,- 138 &,- 041 &,- 561 &,- 623 \\
\hline
\end{tabular}




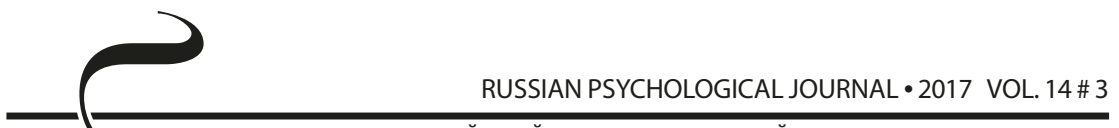

РОССИЙСКИЙ ПСИХОЛОГИЧЕСКИЙ ЖУРНАЛ • 2017 ТОМ 14 № 3

\begin{tabular}{|c|c|c|c|c|}
\hline \multicolumn{5}{|c|}{$\begin{array}{c}\text { Mampuца компонентов }{ }^{a}(n=41) \\
\text { Components matrix }{ }^{a}(n=41)\end{array}$} \\
\hline \multirow{2}{*}{$\begin{array}{c}\text { Характеристики } \\
\text { творчества } \\
\text { Creativity } \\
\text { characteristics } \\
\end{array}$} & \multicolumn{4}{|c|}{$\begin{array}{c}\text { Компоненты (факторы) } \\
\text { Components (factors) }\end{array}$} \\
\hline & 1 & 2 & 3 & 4 \\
\hline $\begin{array}{l}\text { Уровень твор- } \\
\text { чества (по тесту } \\
\text { Э. П. Торренса) } \\
\text { Creativity level } \\
\text { (by Torrance Test) }\end{array}$ & 942 & ,048 & 139 & 103 \\
\hline $\begin{array}{l}\text { Уровень творчества } \\
\text { (по тесту X. Зиверта) } \\
\text { Creativity level } \\
\text { (by Sievert Test) }\end{array}$ &,- 044 & ,874 & 173 & 071 \\
\hline $\begin{array}{l}\text { \% дисперсии } \\
\text { Dispersion } \\
\text { (percentage) }\end{array}$ & 25,270 & 19,282 & 16,438 & 13,348 \\
\hline $\begin{array}{l}\text { Суммарный \% } \\
\text { Sum (percentage) }\end{array}$ & 25,270 & 44,552 & 60,990 & 74,34 \\
\hline
\end{tabular}

1-й фактор включает плеяду напрямую связанных характеристик (оригинальность $(0,648)$, беглость $(0,912)$, разработанность $(0,701)$ и уровень творчества (по тесту Э. П. Торренса) $(0,942))$. В обратной связи с ними находится гибкость $(-0,662)$. Такая структура отражает находчивость, интеллектуальную и творческую способность продуцировать новые оригинальные идеи. Показатель гибкости подчеркивает рефлективную направленность данной структуры.

2-й фактор включает диаду напрямую связанных характеристик (дивергентное мышление $(0,911)$ и уровень творчества (по тесту Х. Зиверта) $(0,874)$ ) и отражает способность к выдвижению новых идей в целом. Дивергентность проявляется при зарождении идей и их проверке [29].

3-й фактор также включает взаимообратную диаду (визуальное творчество $(0,953)$ и способность комбинировать $(-0,561))$. Творческие способности в наглядной сфере не обеспечивают способность конструирования.

4-й фактор включает обратно связанную диаду (находчивость высокого уровня $(0,871)$ и среднего уровня свобода ассоциаций $(-0,623))$. Рефлективные студенты находчивы, но придерживаются определенных схем, однако со временем готовность следовать схемам снижается. Такой факт обусловлен рефлексией как механизмом развития мышления [30].

Структура творческих способностей импульсивных студентов характеризуется пятью факторами (\% совокупной дисперсии - 81,62) (таблица 2). 
Таблица 2.

\section{Факторная матрица взаимосвязей переменных творческих} способностей студентов с импульсивным когнитивным стилем (Rotation Method: Varimax with Kaiser Normalization)

Table 2.

Factorial matrix of associations among the variables of students' creative abilities and the impulsive cognitive style (Rotation Method: Varimax with Kaiser Normalization)

\begin{tabular}{|c|c|c|c|c|c|}
\hline \multicolumn{6}{|c|}{$\begin{array}{c}\text { Mampuца компонентов }{ }^{a}(n=41) \\
\text { Components matrix }{ }^{a}(n=41)\end{array}$} \\
\hline \multirow{2}{*}{$\begin{array}{c}\text { Характеристики } \\
\text { творчества } \\
\text { Creativity } \\
\text { characteristics }\end{array}$} & \multicolumn{5}{|c|}{$\begin{array}{l}\text { Компоненты (факторы) } \\
\text { Components (factors) }\end{array}$} \\
\hline & 1 & 2 & 3 & 4 & 5 \\
\hline $\begin{array}{l}\text { Разработанность } \\
\text { Elaboration }\end{array}$ & ,581 & ,455 & ,346 & 373 &,- 222 \\
\hline $\begin{array}{l}\text { Оригинальность } \\
\text { Originality }\end{array}$ & ,021 &,- 088 & ,889 &,- 112 &,- 051 \\
\hline $\begin{array}{l}\text { Гибкость } \\
\text { Flexibility }\end{array}$ & ,612 & 128 &,- 003 & ,424 & ,440 \\
\hline $\begin{array}{l}\text { Беглость } \\
\text { Fluency }\end{array}$ &,- 870 & 173 & 160 &,- 018 & 116 \\
\hline $\begin{array}{l}\text { Находчивость } \\
\text { Resourcefulness }\end{array}$ & ,688 &,- 004 & 262 &,- 173 & 169 \\
\hline $\begin{array}{l}\text { Комбинирование } \\
\text { Combination }\end{array}$ &,- 047 &,- 033 &,- 016 &,- 094 &,- 969 \\
\hline $\begin{array}{l}\text { Дивергентное } \\
\text { мышление } \\
\text { Divergent } \\
\text { thinking }\end{array}$ & 185 & 342 &,- 382 &,- 581 & ,046 \\
\hline $\begin{array}{l}\text { Визуальное } \\
\text { творчество } \\
\text { Visual creativity }\end{array}$ &,- 405 & ,645 & 163 &,- 213 & ,402 \\
\hline $\begin{array}{l}\text { Свобода } \\
\text { ассоциаций } \\
\text { Freedom of } \\
\text { association }\end{array}$ & 076 & ,009 &,- 059 & ,922 & 122 \\
\hline
\end{tabular}




\begin{tabular}{|c|c|c|c|c|c|}
\hline \multicolumn{6}{|c|}{$\begin{array}{l}\text { Maтрица компонентов }{ }^{a}(n=41) \\
\text { Components matrix }{ }^{a}(n=41)\end{array}$} \\
\hline \multirow{2}{*}{$\begin{array}{c}\text { Характеристики } \\
\text { творчества } \\
\text { Creativity } \\
\text { characteristics } \\
\end{array}$} & \multicolumn{5}{|c|}{$\begin{array}{l}\text { Компоненты (факторы) } \\
\text { Components (factors) }\end{array}$} \\
\hline & 1 & 2 & 3 & 4 & 5 \\
\hline $\begin{array}{l}\text { Уровень твор- } \\
\text { чества (по тесту } \\
\text { Э. П. Торренса) } \\
\text { Creativity level } \\
\text { (by Torrance Test) }\end{array}$ & 125 & 335 & ,816 & 315, & 162 \\
\hline $\begin{array}{l}\text { Уровень твор- } \\
\text { чества (по тесту } \\
\text { Х. Зиверта) } \\
\text { Creativity level } \\
\text { (by Sievert Test) }\end{array}$ & 009 & 968 &,- 008 &,- 023 &,- 019 \\
\hline $\begin{array}{l}\text { \% дисперсии } \\
\text { Dispersion } \\
\text { (percentage) }\end{array}$ & 19,545 & 16,795 & 16,792 & 15,482 & 13,001 \\
\hline $\begin{array}{l}\text { Суммарный \% } \\
\text { Sum (percentage) }\end{array}$ & 19,545 & 36,340 & 53,132 & 68,614 & 81,62 \\
\hline
\end{tabular}

1-й фактор включает плеяду напрямую связанных характеристик (разработанность $(0,581)$, гибкость $(0,612)$, находчивость $(0,688))$. Противостоит им беглость $(-0,870)$, ее величина сформирована гораздо выше по модулю в сравнении с тремя указанными характеристиками. Такая взаимосвязь обусловлена стилевой характеристикой группы - импульсивностью.

2-й фактор включает диаду (визуальное творчество $(0,645)$ и уровень творчества по тесту Х. Зиверта $(0,968))$.

3-й фактор дополняет предыдущий. Он включает оригинальность $(0,889)$ и уровень творчества (по тесту Э. П. Торренса) $(0,816)$.

4-й фактор включает дивергентное мышление $(-0,581)$, обратно связанное со свободой ассоциаций $(0,922)$.

5-й фактор является неустойчивым и включает лишь одну отрицательно направленную характеристику - комбинирование $(-0,969)$, например, понятий, предметов и т. д., что свидетельствует о его противопоставлении по отношению к другим факторам.

Структура творческих способностей медленных неточных студентов характеризуется четырьмя факторами (\% совокупной дисперсии - 88,35) (таблица 3). 
Таблица 3.

Факторная матрица взаимосвязей переменных творческих способностей студентов с медленным неточным когнитивным стилем (Rotation Method: Varimax with Kaiser Normalization)

Table 3.

Factorial matrix of associations among the variables of students' creative abilities and the slow-inaccurate cognitive style (Rotation Method:

Varimax with Kaiser Normalization)

\begin{tabular}{|c|c|c|c|c|}
\hline \multicolumn{5}{|c|}{$\begin{array}{c}\text { Maтрича компонентов }{ }^{a}(n=16) \\
\text { Components matrix }{ }^{a}(n=16)\end{array}$} \\
\hline \multirow{2}{*}{$\begin{array}{c}\text { Характеристики } \\
\text { творчества } \\
\text { Creativity } \\
\text { characteristics }\end{array}$} & \multicolumn{4}{|c|}{$\begin{array}{l}\text { Компоненты (факторы) } \\
\text { Components (factors) }\end{array}$} \\
\hline & 1 & 2 & 3 & 4 \\
\hline $\begin{array}{l}\text { Разработанность } \\
\text { Elaboration }\end{array}$ & ,633 & 073 & 106 & 141 \\
\hline $\begin{array}{l}\text { Оригинальность } \\
\text { Originality }\end{array}$ & ,630 & 373 &,- 177 & ,440 \\
\hline $\begin{array}{l}\text { Гибкость } \\
\text { Flexibility }\end{array}$ &,- 119 &,- 712 &,- 069 & ,473 \\
\hline $\begin{array}{l}\text { Беглость } \\
\text { Fluency }\end{array}$ & ,542 &,- 422 &,- 356 &,- 201 \\
\hline $\begin{array}{l}\text { Находчивость } \\
\text { Resourcefulness }\end{array}$ & 375 &,- 060 &,- 784 &,- 057 \\
\hline $\begin{array}{l}\text { Комбинирование } \\
\text { Combination }\end{array}$ & 374 &,- 189 &,- 162 & ,827 \\
\hline $\begin{array}{l}\text { Дивергентное } \\
\text { мышление } \\
\text { Divergent thinking }\end{array}$ & 363 &,- 284 & 794 &,- 206 \\
\hline $\begin{array}{l}\text { Визуальное } \\
\text { творчество } \\
\text { Visual creativity }\end{array}$ &,- 255 & 819 &,- 249 &,- 040 \\
\hline \begin{tabular}{|l} 
Свобода \\
aссоциаций \\
Freedom of \\
association
\end{tabular} &,- 189 & 263 & ,813 &,- 164 \\
\hline
\end{tabular}




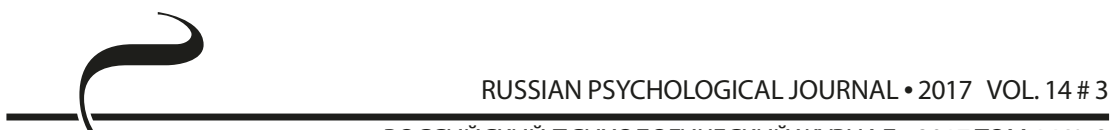

РОССИЙСКИЙ ПСИХОЛОГИЧЕСКИЙ ЖУРНАЛ • 2017 ТОМ 14 № 3

\begin{tabular}{|c|c|c|c|c|}
\hline \multicolumn{5}{|c|}{$\begin{array}{l}\text { Maтрица компонентов }{ }^{a}(n=16) \\
\text { Components matrix }{ }^{a}(n=16)\end{array}$} \\
\hline \multirow{2}{*}{$\begin{array}{c}\text { Характеристики } \\
\text { творчества } \\
\text { Creativity } \\
\text { characteristics } \\
\end{array}$} & \multicolumn{4}{|c|}{$\begin{array}{l}\text { Компоненты (факторы) } \\
\text { Components (factors) }\end{array}$} \\
\hline & 1 & 2 & 3 & 4 \\
\hline $\begin{array}{l}\text { Уровень твор- } \\
\text { чества (по тесту } \\
\text { Э. П. Tорренса) } \\
\text { Creativity level } \\
\text { (by Torrance Test) }\end{array}$ & 744 &,- 122 &,- 156 & 231 \\
\hline $\begin{array}{l}\text { Уровень твор- } \\
\text { чества (по тесту } \\
\text { X. Зиверта) } \\
\text { Creativity level } \\
\text { (by Sievert Test) }\end{array}$ & ,092 & 695 & 360, & ,026 \\
\hline $\begin{array}{l}\text { \% дисперсии } \\
\text { Dispersion } \\
\text { (percentage) }\end{array}$ & 31,141 & 24,376 & 21,105 & 11,724 \\
\hline $\begin{array}{l}\text { Суммарный \% } \\
\text { Sum (percentage) }\end{array}$ & 31,141 & 55,517 & 76,621 & 88,35 \\
\hline
\end{tabular}

1-й фактор включает плеяду напрямую связанных характеристик (разработанность $(0,633)$, оригинальность $(0,630)$, беглость $(0,542)$, средний уровень творчества (по тесту Э. П. Торренса) $(0,744))$. В целом, он отражает способность выдвигать идеи и разрабатывать их, однако уровень сформированности этих характеристик недостаточно высок.

2-й фактор включает диаду визуального творчества $(0,819)$, связанного со средним уровнем творчества (по тесту Х. Зиверта) (0,695). Обратно с ними связана гибкость $(-0,712)$, что обусловлено стилевой характеристикой студентов группы.

3-й фактор также включает диаду (свобода ассоциаций $(0,813)$, дивергентное мышление $(0,794))$. В обратной связи с ними находится находчивость $(-0,784)$. Они демонстрируют находчивость, но недостаточно развитые дивергентное мышление и свобода ассоциаций подчеркиваются непродуктивностью стилевой характеристики и учебной деятельности студентов, что согласуется с исследованиями В. Н. Дружинина, М. А. Холодной.

4-й фактор является неустойчивым, т. к. включает лишь комбинирование $(0,827)$, что отражает потенциал студентов в способности к комбинированию, однако в настоящий момент низкого уровня.

Структура творческих способностей быстрых точных студентов характеризуется пятью факторами (\% совокупной дисперсии - 82,47) (таблица 4). 
Таблица 4.

\section{Факторная матрица взаимосвязей переменных творческих} способностей студентов с быстрым точным когнитивным стилем (Rotation Method: Varimax with Kaiser Normalization)

Table 4.

Factorial matrix of associations among the variables of students' creative abilities and the fast-accurate cognitive style (Rotation Method: Varimax with Kaiser Normalization)

\begin{tabular}{|c|c|c|c|c|c|}
\hline \multicolumn{6}{|c|}{$\begin{array}{c}\text { Mampuца компонентов }{ }^{a}(n=38) \\
\text { Components matrix }{ }^{a}(n=38)\end{array}$} \\
\hline \multirow{2}{*}{\begin{tabular}{|c|} 
Характеристики \\
творчества \\
Creativity \\
characteristics \\
\end{tabular}} & \multicolumn{5}{|c|}{$\begin{array}{c}\text { Компоненты (факторы) } \\
\text { Components (factors) }\end{array}$} \\
\hline & 1 & 2 & 3 & 4 & 5 \\
\hline $\begin{array}{l}\text { Разработанность } \\
\text { Elaboration }\end{array}$ & ,893 &,- 006 & 212 &,- 206 & ,035 \\
\hline $\begin{array}{l}\text { Оригинальность } \\
\text { Originality }\end{array}$ &,- 094 & ,857 & 111 & 142 &,- 198 \\
\hline $\begin{array}{l}\text { Гибкость } \\
\text { Flexibility }\end{array}$ & 383 &,- 189 &,- 142 & 284 & 749, \\
\hline $\begin{array}{l}\text { Беглость } \\
\text { Fluency }\end{array}$ & 943 &,- 324 &,- 457 &,- 295 & 037 \\
\hline $\begin{array}{l}\text { Находчивость } \\
\text { Resourcefulness }\end{array}$ &,- 385 & 249 & ,677 &,- 263 & 351 \\
\hline $\begin{array}{l}\text { Комбинирование } \\
\text { Combination }\end{array}$ &,- 220 &,- 556 &,- 091 & 656 &,- 331 \\
\hline $\begin{array}{l}\text { Дивергентное } \\
\text { мышление } \\
\text { Divergent thinking }\end{array}$ & 380 &,- 345 & 765 & 184 &,- 012 \\
\hline $\begin{array}{l}\text { Визуальное } \\
\text { творчество } \\
\text { Visual creativity }\end{array}$ & ,627 & 403 &,- 401 & 093 &,- 082 \\
\hline $\begin{array}{l}\text { Свобода } \\
\text { ассоциаций } \\
\text { Freedom of } \\
\text { association }\end{array}$ &,- 372 & ,509 &,- 388 & 309 & ,343 \\
\hline
\end{tabular}




\begin{tabular}{|c|c|c|c|c|c|}
\hline \multicolumn{6}{|c|}{$\begin{array}{l}\text { Mampuца компонентов }{ }^{a}(n=38) \\
\text { Components matrix }{ }^{a}(n=38)\end{array}$} \\
\hline \multirow{2}{*}{$\begin{array}{c}\text { Характеристики } \\
\text { творчества } \\
\text { Creativity } \\
\text { characteristics }\end{array}$} & \multicolumn{5}{|c|}{$\begin{array}{c}\text { Компоненты (факторы) } \\
\text { Components (factors) }\end{array}$} \\
\hline & 1 & 2 & 3 & 4 & 5 \\
\hline $\begin{array}{l}\text { Уровень твор- } \\
\text { чества (по тесту } \\
\text { Э. П. Торренса) } \\
\text { Creativity level } \\
\text { (by Torrance Test) }\end{array}$ & 732 & 481 & 156 &,- 050 &,- 219 \\
\hline $\begin{array}{l}\text { Уровень твор- } \\
\text { чества (по тесту } \\
\text { X. Зиверта) } \\
\text { Creativity level } \\
\text { (by Sievert Test) }\end{array}$ & ,472 & 220 & 272 & 718 & ,050 \\
\hline $\begin{array}{l}\text { \% дисперсии } \\
\text { Dispersion } \\
\text { (percentage) }\end{array}$ & 26,013 & 18,799 & 15,887 & 12,594 & 9,179 \\
\hline $\begin{array}{l}\text { Суммарный \% } \\
\text { Sum (percentage) }\end{array}$ & 26,013 & 44,812 & 60,699 & 73,293 & 82,473 \\
\hline
\end{tabular}

1-й фактор включает плеяду напрямую связанных характеристик (беглость $(0,943)$, визуальное творчество $(0,627)$, разработанность $(0,893)$, высокий уровень творчества (по тесту Э. П. Торренса) $(0,732))$. Студенты способны быстро выдвигать новые разработанные идеи высокого уровня.

2-й фактор включает высоко развитую диаду (оригинальность $(0,857)$, свобода ассоциаций $(0,509))$.

3-й фактор также включает высоко развитую диаду (находчивость $(0,677)$, дивергентное мышление $(0,765))$.

4-й фактор включает еще одну высоко развитую диаду (комбинирование $(0,656)$, уровень творчества (по тесту Х. Зиверта) $(0,718)$ ).

5-й фактор включает лишь одну характеритику - гибкость $(0,749)$. В силу этого он является неустойчивым, но ее положительная направленность и высокий уровень отражают способность продуктивно использовать разные способы в процессе решения задач и проблем.

Необходимо отметить, что положительная направленность всех характеристик данной структуры отражает ее гармоничность. Такой эффект наблюдается лишь в группе студентов с быстрым точным когнитивным стилем. 


\section{Заключение}

В заключение можно сделать выводы: 1) студенты вуза неравномерно распределяются по стилевым характеристикам (рефлективные - 30\%, быстрые точные - 28\%, импульсивные - 30\%, медленные неточные - $12 \%$ ); 2) суммарный процент студентов с продуктивными когнитивными стилями (рефлективным и быстрым точным) - 58\%, что значимо отличается (по угловому преобразованию Фишера: $\left.\varphi^{*}{ }_{\text {эмп. }}=2,688, \mathrm{p} \leq 0,05\right)$ от процента студентов с непродуктивными когнитивными стилями (импульсивным и медленным неточным) - $42 \%$. Однако непродуктивность когнитивных стилей среди студентов определяет задачи дополнительного изучения их стилевых характеристик.

В процессе эмпирического исследования взаимосвязи быстрого точного когнитивного стиля и творческих показателей получены факты, которые позволяют назвать этот стиль предиктором творческих способностей студентов. Доминирование высокой академической успеваемости у студентов с рефлективным когнитивным стилем отражает предикторный потенциал данного стиля студентов в учебной деятельности.

Полученные эффекты обусловлены значимым отличием студентов с рефлективным когнитивным стилем по сформированности у них разработанности и гибкости, а также значимым отличием студентов с быстрым точным когнитивным стилем по сформированности у них беглости, гибкости, оригинальности.

Полученные результаты, согласуются с выводами М. А. Холодной об опосредованной обусловленности когнитивными стилями индивидуальности творческого ума, что, на наш взгляд, открывает перспективы исследования предикторного потенциала творческо-стилевых структур студентов как будущих профессионалов.

\section{Литература}

1. Азаров В.Н. Структура импульсивного и рефлексивно-волевого стилей поведения // Вопросы психологии. - 1988. - № 3. - С. 132-138.

2. Коломиец Е. Ф. Когнитивные аспекты современного исследования креативности // Ананьевские чтения - 2008: Психология кризисных и экстремальных ситуаций: междисциплинарный подход : материалы научно-практической конференции / под ред. Л. А. Цветковой, Н. С. Хрусталевой. - СПб. : Изд-во Санкт-Петербургского университета, 2008. - С. 201-202.

3. Дружинин В.Н. Психология общих способностей. - СПб. : Питер, 2007. 3-е изд. - 368 с.

4. Кострикина И.С. Соотношение стилевых и продуктивных характеристик интеллектуальной деятельности у лиц с высокими значениями IQ : дисс. ... канд. психол. наук. - М., 2001. - 207 с. 
5. Холодная М.А. Когнитивные стили. О природе индивидуального ума. СПб. : Питер, 2004. - 2-е изд. - 384 с.

6. Холодная М.А. Феномен «расщепления» полюсов когнитивных стилей // Интеллект и творчество : Сборник научных трудов / отв. ред. А. Н. Воронин. - М. : Изд-во ИП РАН, 1999. - 46 с.

7. Грановская Р.М. Конфликт и творчество в зеркале психологии. - М. : Генезис, 2002. - 573 с.

8. Большой психологический словарь / В. П. Зинченко ; сост. Б. Г. Мещеряков. - СПб. : Олма-пресс ; М. : Прайм-еврознак, 2004. - 666 с.

9. Collell G., Fauquet J. How the Relationship Between Information Theory and Thermodynamics Can Contribute to Explaining Brain and Cognitive Activity: an Integrative Approach // COGNITIVE2014: The Sixth International Conference on Advanced Cognitive Technologies and Applications. (Venice, Italy). - NY : Curran Associates Inc., 2014. - P. 269-273.

10. Torrance E. P. The Nature of Creativity as Manifest in its Testing // R. Sternberg (ed.) The Nature of Creativity. - Cambridge : Cambridge University Press, 1988. - P. 43-73.

11. Виноградова Т.И. Беглость, гибкость и оригинальность как основные компоненты в структуре креативности // Научно-исследовательские публикации. - 2014. - № 4 (8). - С. 104-108.

12. Щебланова Е.И. Теория и тесты творческого мышления Е. П. Торренса // Психологическая диагностика. - 2004. - № 11. - С. 3-20.

13. Краткий психологический словарь / под общ. ред. А. В. Петровского, М. Г. Ярошевского. - Ростов н/Д : Феникс, 1999. - 494 с.

14. Кибальченко И. А., Эксакусто Т. В., Истратова О. Н. Интеллектуальноличностный ресурс субъекта развития: теоретические основы : монография. - Таганрог : Изд-во ЮФУ, 2017. - 160 с.

15. Кибальченко И. А., Забалуева А. И. Когнитивные стили студентов ВУЗа // Адизова Д.Р., Алексеева О.В., Алиджанова И.Э. Наука и общество: от теории к практике : монография / под ред. И. М. Ковчиной. - Ставрополь : Логос, 2016. - Книга 2. - 282 с.

16. Толочек В. А. Подобные структуры стилей деятельности как фактор успешности субъекта // Вопросы психологии. - 2015. - № 6. - С. 112-122.

17. Волкова Е.В. Технологии развития ментальных ресурсов. - М. : Изд-во ИП РАН, 2015. - $256 \mathrm{C}$.

18. Дюпина С. А. Когнитивный стиль импульсивность/рефлексивность как фактор эффективности и качественного своеобразия мнемических способностей // Вестник Ярославского государственного университета имени П. Г. Демидова. Серия Гуманитарные науки. - 2013. № 3. - С. 79-81. 
19. Величковский Б. М. Когнитивная наука: Основы психологии познания : в 2 т. - М. : Смысл ; Издательский центр «Академия», 2006. - Т. 2. - 432 с.

20. Холодная М. А. Психология понятийного мышления: От концептуальных структур к понятийным способностям. - М. : Изд-во ИП РАН, 2012. - 288 с.

21. Психология способностей: Современное состояние и перспективы исследований : Материалы научной конференции, посвященной памяти В. Н. Дружинина, ИП РАН, 19-20 сентября 2005 г. / под ред. А. Л. Журавлева, М. А. Холодной. - М. : Изд-во ИП РАН, 2005. - 477 с.

22. Mackintosh N.J. IQ and human intelligence. - Oxford : Oxford University Press, 2011. $-2^{\text {nd }}$ ed. -456 p.

23. Кибальченко И. А. Интеграция учебного и познавательного опыта обучающихся: структура, динамика, технологии : дисс. ... д. психол. наук. - Ростов н/Д, 2011. - 364 с.

24. Kagan J. Reflection-impulsivity: The generality and dynamics of conceptual tempo // Journal of Abnormal Psychology. - 1966. - Vol. 71. - P. 17-24.

25. Зиверт X. Тестирование личности : Пер. с нем. - М. : АО «Интерэксперт», 1998. - 2-е изд. - 198 с.

26. Кибальченко И. А. Взаимосвязь субъектного, ментального и познавательного опыта у лиц с разной успешностью деятельности // Психологический журнал. - 2010. - № 3. - С. 33-45.

27. Jones A. E. Reflection-impulsivity and wholist-analytic: Two fledglings? Or is R-I a cuckoo? // Educational Psychology. - 1997. - Vol. 17 (1-2). - P. 65-77.

28. Сидоренко Е. В. Методы математической обработки в психологии. - СПб. : Речь, 2004. - 350 c.

29. Захарова С. А. Расчлененность когнитивной сферы и особенности формирования образных обобщений у старших школьников // Вопросы психологии. - 1986. - № 4. - С. 53-62.

30. Shannon S. V. Using Metacognitive Strategies and Learning Styles to Create SelfDirected Learners // Institute for Learning Styles Journal. - 2008. - Vol. 1. - P. 14-28.

\section{References}

1. Azarov V.N. The structure of impulsive and reflective-volitional styles of behavior. Voprosy psikhologii, 1988, no. 3, pp. 132-138 (in Russian).

2. Kolomiets E. F. Kognitivnye aspekty sovremennogo issledovaniya kreativnosti [Cognitive aspects of the modern study of creativity]. Materialy nauchno-prakticheskoi konferentsii "Anan'evskie chteniya - 2008: Psikhologiya krizisnykh i ekstremal'nykh situatsii: mezhdistsiplinarnyi podkhod" [Proc. Theoretical and Practical Conference "Ananiev readings - 2008: Psychology of crisis and extreme situations: An interdisciplinary approach"]. St. Petersburg, St. Petersburg University Publ., 2008, pp. 201-202. 
3. Druzhinin V.N. Psikhologiya obshchikh sposobnostei [Psychology of general abilities]. St. Petersburg, Piter Publ., 2007. 368 p.

4. Kostrikina I.S. Sootnoshenie stilevykh i produktivnykh kharakteristik intellektual'noi deyatel'nosti u lits s vysokimi znacheniyami IQ [Style and productive characteristics of intellectual activity in individuals with high IQ]. Diss. Cand. Sci. (Psych.). Moscow, 2001. 207 p.

5. Kholodnaya M. A. Kognitivnye stili. O prirode individual'nogo uma [Cognitive styles. On the nature of the individual mind]. St. Petersburg, Piter Publ., 2004. 384 p.

6. Kholodnaya M.A. The phenomenon of "splitting" the poles of cognitive styles. In: Voronin A. N. Intellekt i tvorchestvo [Intelligence and creativity]. Moscow, RAS Institute of Psychology Publ., 1999. 46 p.

7. Granovskaya R.M. Konflikt i tvorchestvo v zerkale psikhologii [Creativity and conflict in the mirror psychology]. Moscow, Genezis Publ., 2002. 573 p.

8. Zinchenko V.P. (ed.). Bol'shoi psikhologicheskii slovar' [Large dictionary of psychology]. St. Petersburg, Olma-press Publ., 2004. 666 p.

9. Collell G., Fauquet J. How the relationship between information theory and thermodynamics can contribute to explaining brain and cognitive activity: An integrative approach. COGNITIVE2014: The sixth international conference on advanced cognitive technologies and applications (Venice, Italy). NY, Curran Associates Inc., 2014, pp. 269-273.

10. Torrance E. P. The nature of creativity as manifest in its testing. In: Sternberg R. The nature of creativity. Cambridge: Cambridge University Press, 1988, pp. 43-73.

11. Vinogradova T.I. Fluency, flexibility, and originality as key components of creativity. Nauchno-issledovatel'skie publikatsii - Journal of Scientific Research Publications, 2014, no. 4 (8), pp. 104-108 (in Russian).

12. Shcheblanova E.I. Theory and tests of creative thinking by E. P. Torrance. Psikhologicheskaya diagnostika - Psychological Diagnostics, 2004, no. 11, pp. 3-20 (in Russian).

13. Petrovskii A.V., Yaroshevskii M.G. (eds.). Kratkii psikhologicheskii slovar' [Concise dictionary of psychology]. Rostov-on-Don, Feniks Publ., 1999. 494 p.

14. Kibal'chenko I. A., Eksakusto T.V., Istratova O. N. Intellektual'no-lichnostnyi resurs sub"ekta razvitiya: teoreticheskie osnovy [Intellectual and personal resource of the subject of development:Theoretical foundations]. Taganrog, Southern Federal University Publ., 2017. 160 p.

15. Kibal'chenko I. A., Zabalueva A. I. Cognitive styles of university students. In: Adizova D. R., Alekseeva O.V., Alidzhanova I. E. Nauka i obshchestvo: ot teorii k praktike [Science and society: From theory to practice]. Stavropol, Logos Publ., 2016, V. 2. 282 p. 
16. Tolochek V. A. Similar structures of activity styles as a factor for the subject's success. Voprosy psikhologii, 2015, no. 6, pp. 112-122 (in Russian).

17. Volkova E.V. Tekhnologii razvitiya mental'nykh resursov [Techniques for the development of mental resources]. Moscow, RAS Institute of Psychology Publ., 2015. 256 p.

18. Dyupina S.A. Reflectivity/impulsivity cognitive style as a factor for effectiveness and qualitative originality of mnemonic abilities. Vestnik Yaroslavskogo gosudarstvennogo universiteta im. P. G. Demidova. Serija gumanitarnye nauki, 2013, no. 3, pp. 79-81 (in Russian).

19. Velichkovskii B.M. Kognitivnaya nauka: Osnovy psikhologii poznaniya [Cognitive science: Foundations of the psychology of cognition]. Moscow, Smysl Publ., 2006, V. 2. 432 p.

20. Kholodnaya M. A. Psikhologiya ponyatiinogo myshleniya:Ot kontseptual'nykh strukturkponyatiinym sposobnostyam [Psychology of conceptual thinking: From conceptual structures to conceptual abilities]. Moscow, RAS Institute of Psychology Publ., 2012. 288 p.

21. Zhuravlev A. L., Kholodnaya M. A. (eds.). Psikhologiya sposobnostei: Sovremennoe sostoyanie i perspektivy issledovanii [The psychology of abilities: Current status and prospects of research]. Materialy nauchnoi konferentsii, posvyashchennoi pamyati V. N. Druzhinina [Proc. the Scientific Conference Dedicated to the Memory of V. N. Druzhinin]. Moscow, RAS Institute of Psychology Publ., 19-20 September, 2005. 477 p.

22. Mackintosh N. J. IQ and human intelligence. Oxford, Oxford University Press, $2011.456 \mathrm{p}$.

23. Kibal'chenko I. A. Integratsiya uchebnogo i poznavatel'nogo opyta obuchayushchikhsya: struktura, dinamika, tekhnologii [Integration of students' educational and cognitive experience: Structure, dynamics, and techniques]. Diss. Dr. Sci. (Psych.). Rostov-on-Don, 2011. 364 p.

24. Kagan J. Reflection-impulsivity: The generality and dynamics of conceptual tempo. Journal of Abnormal Psychology, 1966, V. 71, pp. 17-24.

25. Sievert H. Testirovanie lichnosti [Personality testing]. Moscow, Interekspert Publ., 1998. 198 p.

26. Kibal'chenko I. A. The relationships among subjective, mental and cognitive experiences in individuals with different success. Psikhologicheskii zhurnal, 2010, no. 3, pp. 33-45 (in Russian).

27. Jones A. E. Reflection-impulsivity and wholist-analytic: Two fledglings? Or is R-I a cuckoo? Educational Psychology, 1997, V. 17 (1-2), pp. 65-77.

28. Sidorenko E.V. Metody matematicheskoi obrabotki v psikhologii [Methods of mathematical processing in psychology]. St. Petersburg, Rech' Publ., 2004. 350 p. 
РОССИЙСКИЙ ПСИХОЛОГИЧЕСКИЙ ЖУРНАЛ • 2017 ТОМ 14 № 3

29. Zakharova S. A. Compartmentalization of cognitive sphere and features of imaginative generalizations in senior schoolchildren. Voprosy psikhologii, 1986, no. 4, pp. 53-62 (in Russian).

30. Shannon S.V. Using metacognitive strategies and learning styles to create self-directed learners. Institute for Learning Styles Journal, 2008, V. 1, pp. 14-28. 